This document was prepared in conjunction with work accomplished under Contract No. DE-AC09-96SR18500 with the U.S. Department of Energy.

This work was prepared under an agreement with and funded by the U.S. Government. Neither the U. S. Government or its employees, nor any of its contractors, subcontractors or their employees, makes any express or implied: 1 . warranty or assumes any legal liability for the accuracy, completeness, or for the use or results of such use of any information, product, or process disclosed; or 2 . representation that such use or results of such use would not infringe privately owned rights; or 3 . endorsement or recommendation of any specifically identified commercial product, process, or service. Any views and opinions of authors expressed in this work do not necessarily state or reflect those of the United States Government, or its contractors, or subcontractors. 
WSRC-TR-2005-00434

\section{Evaluation of Constant Current Weld Control for Pinch Welding}

By

P.S. Korinko

S.R. Howard

September 2005

Westinghouse Savannah River Company

Aiken, SC 29808

Prepared for the U.S. Department of Energy under Contract DE-AC09-96SR18500 
Evaluation of Constant Current

Weld Control for Pinch Welding
Page i $\quad$ WSRC-TR-2005-00434

This page intentionally left blank 
Evaluation of Constant Current Page ii $\quad$ WSRC-TR-2005-00434

Weld Control for Pinch Welding

WSRC-RP-2005-00434

MST

MATERIALS SCIENCE and TECHNOLOGY

Keywords: $\quad$ Stainless steel

Fill Stems

Pinch welds

Retention: Permanent

\section{Evaluation of Constant Current Weld Control for Pinch Welding}

By

P.S. Korinko

S.R. Howard

Materials Compatibility and Welding Technology Group

ISSUED: $\quad$ September 2005

SRNL SAVANNAH RIVER NATIONAL LABORATORY, AIKEN, SC 29808

Westinghouse Savannah River Company

Prepared for the U.S. Department of Energy under Contract DE-AC09-96SR18500 
Evaluation of Constant Current

Weld Control for Pinch Welding

Document: WSRC-TR-2005-00434

Title: $\quad$ Evaluation of Constant Current Weld Control for Pinch Welding

APPROVALS

9-28-2005

P.S. Korinko, Author

Date

Materials Compatibility and Welding Technology

9-27-2005

S.R. Howard, Author

Date

Materials Compatibility and Welding Technology

10-21-2005

W.L. West, Technical Reviewer

Date

Reservoir Systems Engineering

S.L. West, Manager

$9 / 29 / 2005$

Materials Compatibility and Welding Technology 
Evaluation of Constant Current Page $1 \quad$ WSRC-TR-2005-00434

Weld Control for Pinch Welding

\title{
Evaluation of Constant Current Weld Control for Pinch Welding
}

\begin{abstract}
Modern weld controllers typically use current to control the weld process. SRS uses a legacy voltage control method. This task was undertaken to determine if the improvements in the weld control equipment could be implemented to provide improvements to the process control. The constant current mode of operation will reduce weld variability by about a factor of 4 . The constant voltage welds were slightly hotter than the constant current welds of the same nominal current. The control mode did not appear to adversely affect the weld quality, but appropriate current ranges need to be established and a qualification methodology for both welding and shunt calibrations needs to be developed and documented.
\end{abstract}

\section{Background}

Pinch welding has been successfully used to close and seal tritium containing reservoirs for over 50 years. The mechanical objects used to seal the vessels have changed over time and the electrical equipment has been modified and replaced. Today, the pinch welding process uses a commercial, solid state weld controller to function as a simple switch to turn welding current on and off for a precise interval. The weld heat, measured in terms of weld current, must be varied to address the process variables. An operator controls the weld heat by manually setting the output voltage with a variable transformer called a Powerstat. This control mechanism is known as a constant voltage weld process. The voltage and the cumulative series resistance of the system determine the resulting weld current. Weld qualifications are established by demonstrating the weld integrity produced by welding within certain force and voltage parameters for a specified number of weld cycles. The welding engineer must use prior experience and previous weld data to determine the controlling voltage as a starting point with test welds and then control the voltage to achieve the desired weld current in the process. Since the current is really the primary welding variable, a controller that controls current should result in more reproducible weld conditions.

Powerstats are used at SRS for historical reasons. Today, those reasons are no longer present. Like most commercial weld controllers, the Medar controllers that are in use in the loading lines in Defense Programs are capable of controlling the weld heat by varying the phase angle of firing of the SCRs (silicon control rectifiers). The Medar controller also has the capability of introducing a feedback mechanism using the measured weld current to control the actual current or \% I (percent current), real-time during the weld, to drive the current to a programmed target value. This technique has been successfully demonstrated with the reclamation weld process and is in use in production.

This PDRD task was undertaken to investigate the suitability of using constant current to control pinch welding. Test welds were made to evaluate the reproducibility of the process and to 
Evaluation of Constant Current Page 2 WSRC-TR-2005-00434

Weld Control for Pinch Welding

determine the effects on the bond. All welds were confined pinch welds using a nominal 1250 lbs force, 12 cycles, and current as indicated. The welds were made in both air (constant current and welds identified only as CV \#\#\#\#-3) and nitrogen (welds identified as DOEx-2).

\section{Results}

Preliminary work was conducted to determine the relative stability of the process and to see if the constant current process offered improvements over the constant voltage mode of operation. These preliminary results are indicted in Table 1 which shows that the constant current mode of operation reduces the variability of the current from a maximum of $125 \mathrm{~A}$ to less than $25 \mathrm{~A}$. Based on these results additional machine and metallurgical tests were performed. In the testing reported for the latest study, the set-point voltage was not altered between welds so the resultant current for the constant voltage control was more consistent than indicated in Table 1.

The test matrix used for this study is shown in Tables 2 and 3 for both the machine settings and results. Welds were made under cold (3200 A), Nominal (3750 A) and Hot (4000 A) conditions for both constant current and constant voltage control using the same weld control program at 1250 Lbs force and 12 cycles with 3/16" radius tungsten tipped copper electrodes. The different control methods exhibit distinct electrical characteristics for delivering the current to the welder. In the constant voltage mode, the current data forms a continuous sinusoidal wave while the constant current mode results in a chopped wave as shown in Figure 1a and 1b. The current data for two data series are overlaid in Figure 2. The chopped sine wave is apparent in both Figures 1 and 2.

The effect of the different control methods on the metallurgical bond was evaluated by examining both transverse and longitudinal cross-sections of the tubes. It is apparent that the weld heat for the constant voltage mode is somewhat greater than that for the constant current mode due to the presence of melting. This attribute is especially obvious for the welds made at nominally $4000 \mathrm{~A}$ in which the constant voltage mode has a sizeable weld nugget and the constant current sample does not, as shown in Figure 3. The calculated weld heat is similar for both the constant current and constant voltage controlled welds.

The relative difference in weld heat can also be noted by the closure length data listed in Table 3 . The closure length data comparing the two methods is shown graphically in Figure 4. The closure length is consistently greater for the constant voltage by 0.016 to .008 " between 3200 and $4000 \mathrm{~A}$. Note that the closure lengths for the constant current test welds are more consistent than those for the constant voltage test welds.

\section{Conclusions}

The constant current mode of control for pinch welds exhibits less variability than constant voltage control when the set-point is changed for each weld.

The current control welds in this study were cooler than the voltage control welds. 
Evaluation of Constant Current

Weld Control for Pinch Welding

The weld closure lengths for the constant current welds were more consistent than the closure lengths for the constant voltage welds.

\section{Recommendations}

The constant current mode of control offers improvements in weld consistency. However, additional testing is needed to develop comparable weld heats for the two control methods. Also, the effects of different weld heads or system inductance on weld consistency for constant current control needs to be determined since all of these welds were made under nearly identical conditions on a single weld head.

\section{Acknowledgements}

The authors would like to acknowledge financial support from Defense Programs under the auspices of PDRD and R. Rabun. We would also like to thank Tony Curtis for his metallographic sample preparation and photography. We would also like to acknowledge J.M. Tarpley for his electrical engineering design and implementation and contributions to the project.

Table 1. Initial data sets showing relative improvement of constant current control over constant voltage control, bold values are for comparison..

\begin{tabular}{|r|r|r|c|c|c|c|c|c|r||}
\hline Current & $\begin{array}{c}\text { CPW } \\
\text { Tube }\end{array}$ & $\begin{array}{c}\text { UPW } \\
\text { Tube }\end{array}$ & $\begin{array}{c}\text { UPW } \\
\text { Stem }\end{array}$ & $\begin{array}{c}\text { CPW } \\
\text { Stem }\end{array}$ & $\begin{array}{c}\text { CV } \\
\text { Min }\end{array}$ & $\begin{array}{c}\text { CV } \\
\text { Max }\end{array}$ & $\begin{array}{l}\text { CC } \\
\text { CPW }\end{array}$ & $\begin{array}{c}\text { CC } \\
\text { min }\end{array}$ & $\begin{array}{c}\text { CC } \\
\text { max }\end{array}$ \\
\hline 3000 & 3097 & 3002 & 2896 & & 2884.7 & 3104 & 3097.6 & 3094.6 & 3108.5 \\
\hline 3000 & 3104 & 2928 & 2976 & & Range & $\mathbf{2 1 9 . 3}$ & 3108.5 & Range & $\mathbf{1 3 . 9}$ \\
\hline 3000 & & 3061 & 2886.5 & & & & 3094.6 & & \\
\hline 3000 & & 3053 & 2968.8 & & & & 3105 & & \\
\hline 3000 & & 3060 & 2884.7 & & & & 3104.3 & & \\
\hline 3000 & & & 2961 & & & & & & \\
\hline 3500 & 3515 & 3543 & 3453 & & 3441.4 & 3543 & 3587 & 3562.1 & 3587 \\
\hline 3500 & & & 3441.4 & & Range & $\mathbf{1 0 1 . 6}$ & 3562.1 & Range & $\mathbf{2 4 . 9}$ \\
\hline 3500 & & & 3443.6 & & & & 3580.4 & & \\
\hline 3500 & & & 3445.3 & & & & & & \\
\hline 4000 & 3956 & 3913 & 3894 & 4086 & 3869 & 4121 & 3991 & 3986 & 3995.6 \\
\hline 4000 & 3966 & 3931 & 4002 & 4121 & Range & $\mathbf{2 5 2}$ & 3995.6 & Range & $\mathbf{9 . 6}$ \\
\hline 4000 & 3869 & 4080 & 3908.9 & 4011.4 & & & 3986 & & \\
\hline 4000 & 3876 & 3926 & 4018.9 & 4057.3 & & & & & \\
\hline 4000 & & 3958 & 3903.7 & 4047.4 & & & & & \\
\hline 4000 & & & 4003.7 & 4049.4 & & & & & \\
\hline
\end{tabular}


Table 2. Weld conditions and weld machine outputs for test matrix

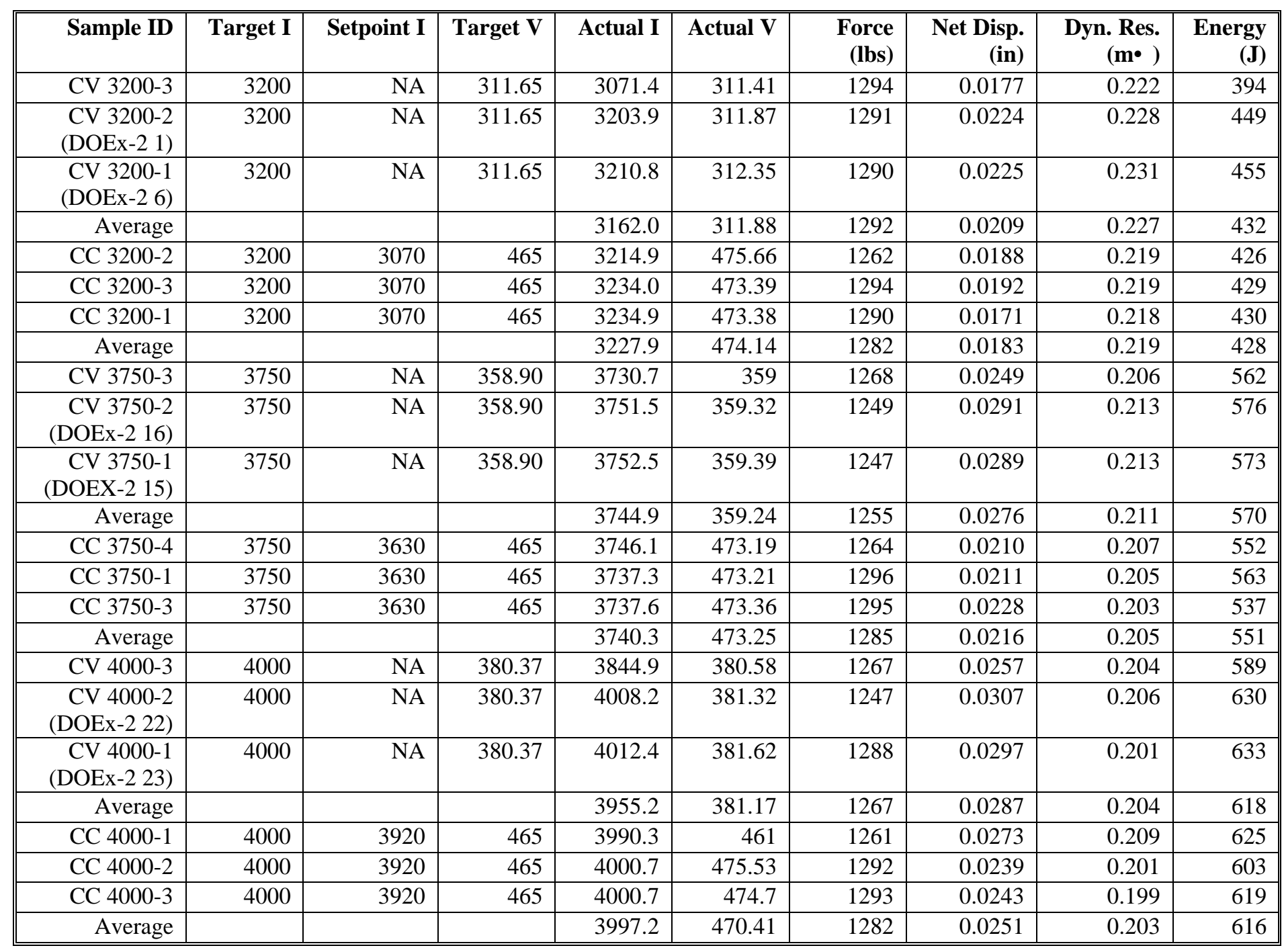


Table 3. Weld quality metrics

\begin{tabular}{|c|c|c|c|c|c|c|c|c|c|}
\hline Sample ID & $\begin{array}{l}\text { Electr. Align } \\
(<.01 \text { ') }\end{array}$ & $\begin{array}{l}\text { Closure } \\
\text { len. (in) }\end{array}$ & Extrusion & $\begin{array}{l}\text { Extrusion to } \\
\text { base }(<1)\end{array}$ & $\begin{array}{l}10 \text { mil } \\
\text { ball (in) }\end{array}$ & $\begin{array}{l}\text { Bond } \\
\text { rating }\end{array}$ & Comments & $\begin{array}{l}\text { Weld thick. } \\
\text { (in) }\end{array}$ & $\begin{array}{l}\text { Weld Width } \\
\text { (in) }<.130\end{array}$ \\
\hline CV 3200-3 & 0.004 & 0.0604 & N/A & N/A & Fails & 3 & Longitudinal & 0.055 & 0.126 \\
\hline $\begin{array}{l}\text { CV 3200-2 } \\
(\mathrm{DOEx}-21)\end{array}$ & 0.001 & 0.0904 & N/A & N/A & Fails & 3 & Continuous interface & 0.055 & 0.126 \\
\hline $\begin{array}{l}\text { CV 3200-1 } \\
(\text { DOEx-2 6) }\end{array}$ & 0.001 & 0.0937 & N/A & N/A & Fails & 3 & $\begin{array}{l}\text { Some broken up interface at } \\
\text { ends }\end{array}$ & 0.0555 & 0.127 \\
\hline Average & & 0.0815 & & & & & & & \\
\hline CC 3200-2 & 0.001 & 0.0733 & N/A & N/A & Fails & 3 & & 0.055 & 0.125 \\
\hline CC 3200-3 & 0.001 & 0.0771 & N/A & N/A & Fails & 3 & & 0.055 & 0.126 \\
\hline CC 3200-1 & 0 & 0.0762 & N/A & N/A & Fails & NA & & 0.055 & 0.126 \\
\hline Average & & 0.0755 & & & & & & & \\
\hline CV 3750-3 & 0.007 & 0.1450 & 0.0049 & 0.36 & N/A & 2 & & 0.049 & 0.124 \\
\hline $\begin{array}{l}\text { CV 3750-2 } \\
\text { (DOEx-2 16) }\end{array}$ & 0.004 & 0.1545 & 0.02 & 0.89 & N/A & 2 & slight melting & 0.051 & 0.126 \\
\hline $\begin{array}{l}\text { CV 3750-1 } \\
(\mathrm{DOEX}-215)\end{array}$ & 0.003 & 0.1540 & 0.0168 & 0.77 & N/A & 2 & Slight melting & 0.05 & 0.126 \\
\hline Average & & 0.1512 & & & & & & & \\
\hline CC 3750-4 & 0.001 & 0.1410 & 0.0049 & 0.32 & N/A & 2 & Longitudinal & 0.051 & 0.126 \\
\hline CC 3750-1 & 0.003 & 0.1405 & 0.0039 & 0.29 & N/A & & & 0.05 & 0.126 \\
\hline CC 3750-3 & 0.005 & 0.1382 & 0.0025 & 0.23 & N/A & 2 & No melt & 0.05 & 0.126 \\
\hline Average & & 0.1399 & & & & & & & \\
\hline CV 4000-3 & 0.007 & 0.1537 & 0.0133 & 0.72 & N/A & 2 & Longitudinal & 0.048 & 0.126 \\
\hline $\begin{array}{l}\text { CV 4000-2 } \\
\text { (DOEx-2 22) }\end{array}$ & 0.005 & 0.1691 & 0.0273 & 1.08 & N/A & 1 & $\begin{array}{l}\text { Nugget, some non linear } \\
\text { decoration in centerline }\end{array}$ & 0.048 & 0.126 \\
\hline $\begin{array}{l}\text { CV 4000-1 } \\
(\mathrm{DOEx}-2 \text { 23) }\end{array}$ & 0.005 & 0.1686 & 0.0244 & 0.97 & N/A & 2 & $\begin{array}{l}\text { Nugget discontinuous } \\
\text { interface }\end{array}$ & 0.048 & 0.126 \\
\hline Average & & 0.1638 & & & & & & & \\
\hline CC 4000-1 & 0.004 & 0.1635 & 0.0116 & 0.59 & N/A & 2 & & 0.046 & 0.124 \\
\hline CC 4000-2 & 0.001 & 0.1597 & 0.0125 & 0.59 & N/A & 2 & & 0.046 & 0.125 \\
\hline CC 4000-3 & 0.001 & 0.1601 & 0.0148 & 0.81 & N/A & 2 & Longitudinal & 0.046 & 0.125 \\
\hline Average & & 0.1611 & & & & & & & \\
\hline
\end{tabular}

Limits and notes: Electrode alignment <0.010", minimum wall thickness 0.020", Closure length 0.100" minimum, Extrusion ratio <1, Bond rating 1 or 2 , thickness $0.045-0.070$ ", width $<0.130$ ". 


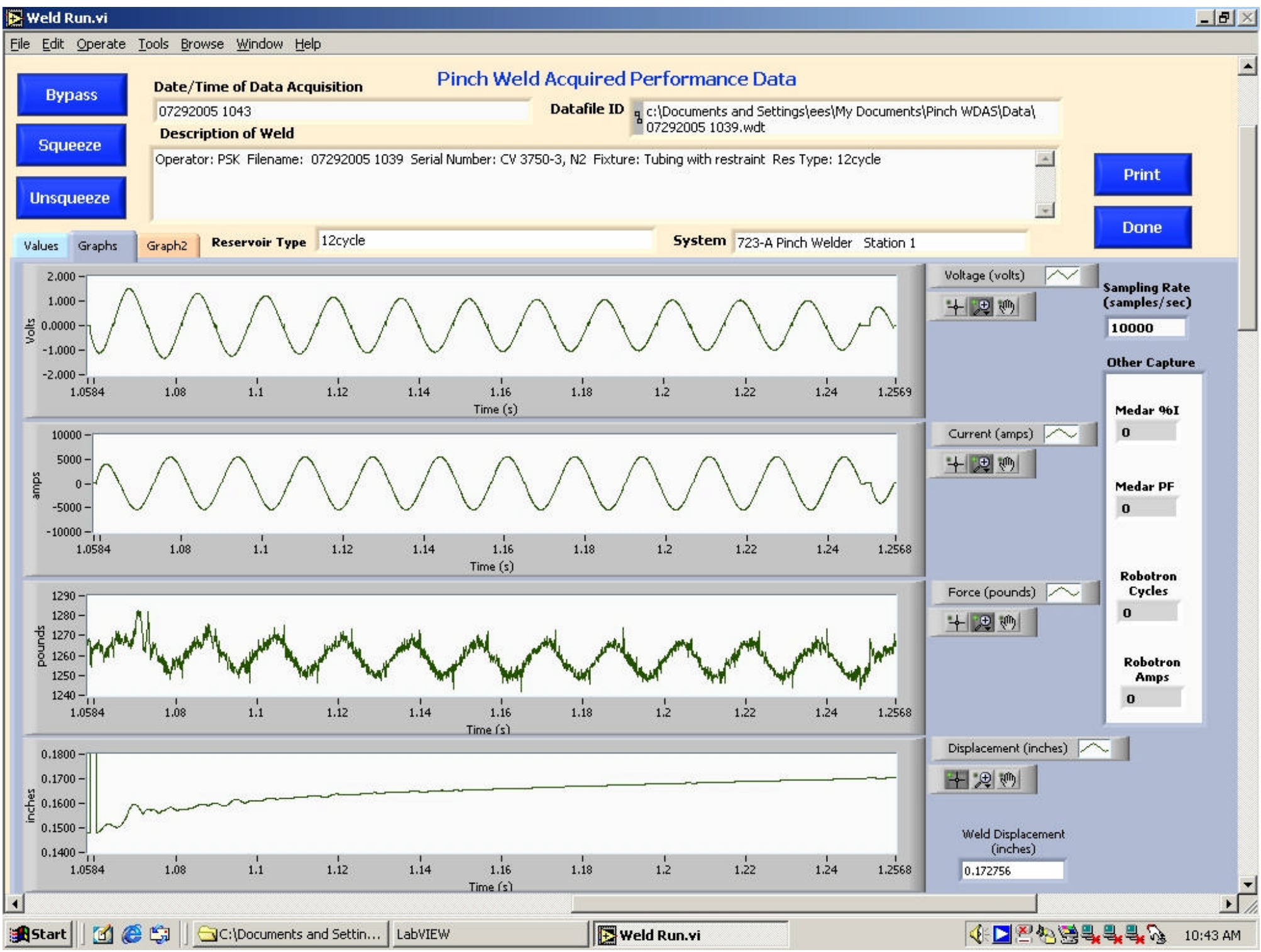

Figure 1(a) Typical data acquisition curves for a constant voltage control pinch weld 


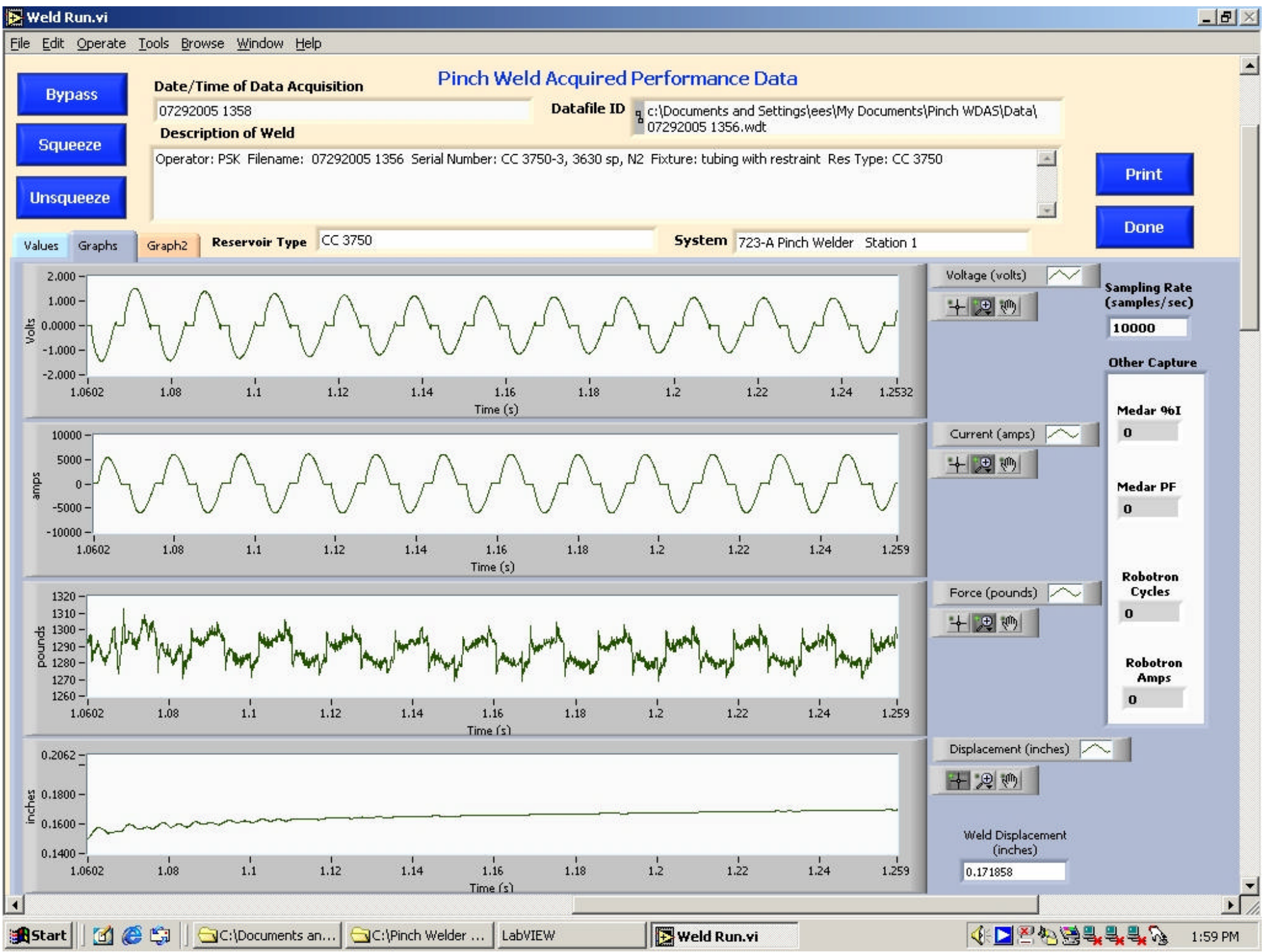

Figure 1. Typical data acquisition curves for (a) constant voltage and (b) constant current control pinch welds. 


\section{Weld Control for Pinch Welding}

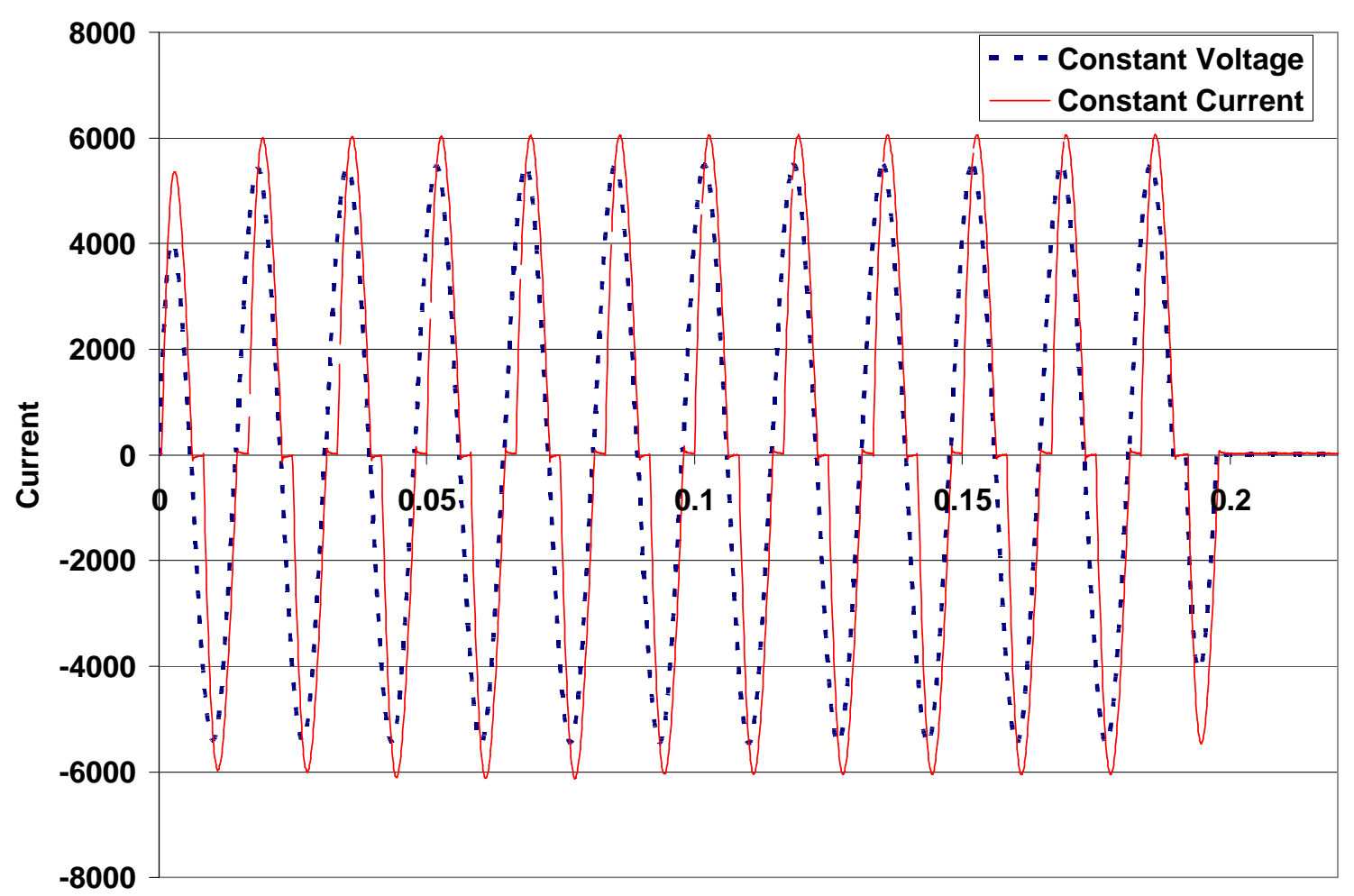

Time (s)

Figure 2. Overlay of current data for constant current and constant voltage control for the nominal 3750 A welds. Note that current is reported as RMS current not instantaneous current as shown in graph.

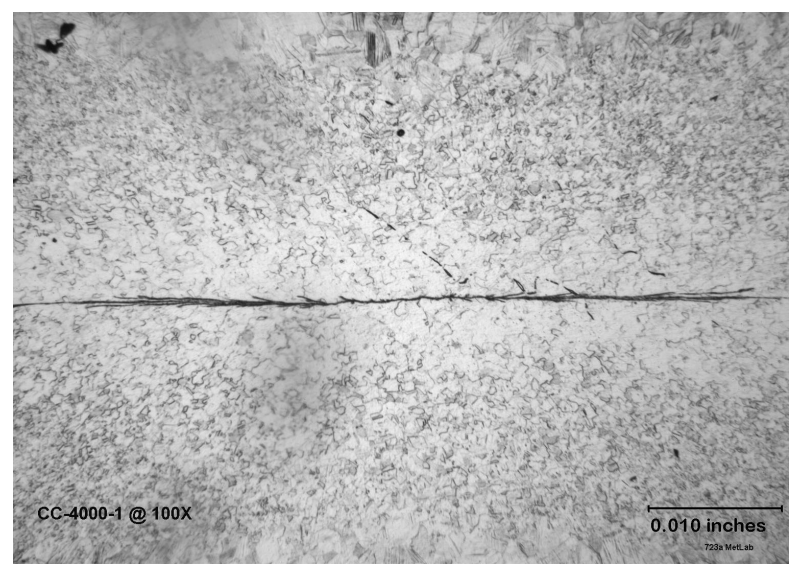

(a)

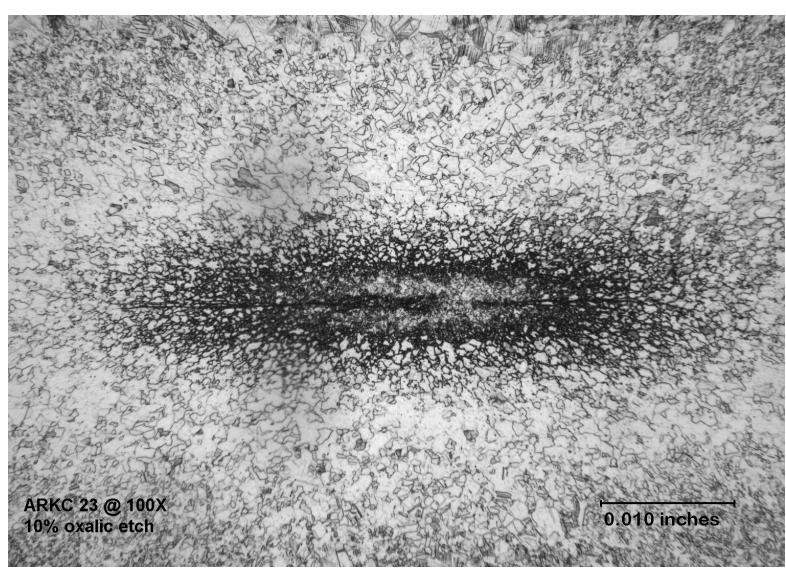

(b)

Figure 3. Comparison of (a) constant current and (b) constant voltage micrograph after welding at nominally $4000 \mathrm{~A}$. The weld heat delivered for constant current is apparently lower than for constant voltage based on presence of nugget despite exhibiting comparable calculated energy. 
Evaluation of Constant Current Page $9 \quad$ WSRC-TR-2005-00434

Weld Control for Pinch Welding

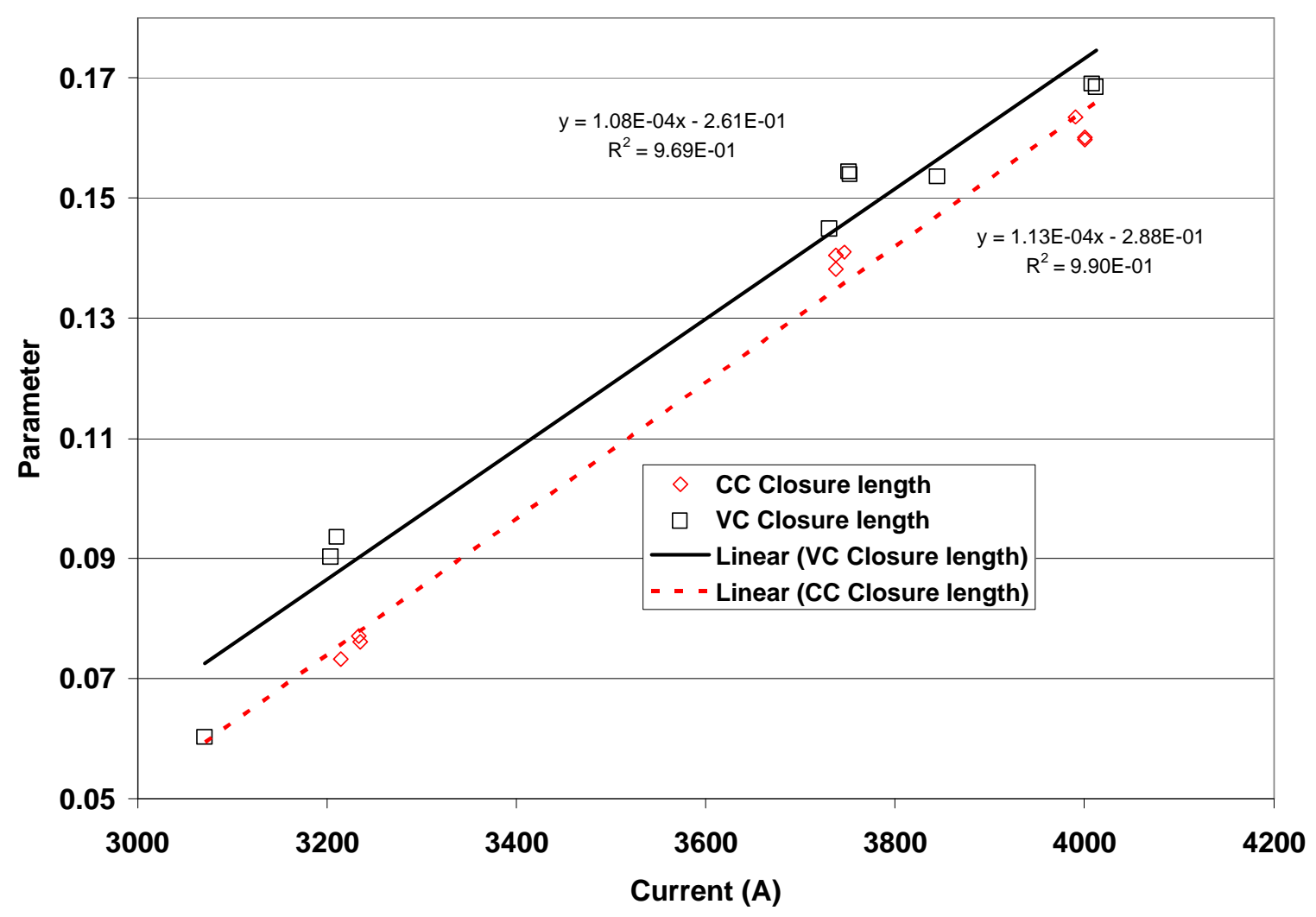

Figure 4. Comparison of closure length for current and voltage control. 
Weld Control for Pinch Welding

\section{Distribution}

S.L. West SRNL

S. Mazurek SRS

E.A Clark SRNL

C. Pretzel SNL

K Hicken SNL

S. Robinson SNL

B. Wilkinson LANL

D Lohmeier LANL

P. Korinko SRNL

B. West SRS

R. Rabun SRS

N.C. Iyer SRNL 